\title{
The Effect of Leadership Style, Professional Competence, and Work Discipline Toward Work Effectiveness
}

\author{
Yudo Dwiyono \\ Faculty of Teacher Training and Education, Mulawarman University, Samarinda, East Kalimantan, Indonesia \\ yudodwiyono@yahoo.co.id
}

\begin{abstract}
The aims of this research were to study the effect of principals' leadership style, the professional competence, and the teachers disciplinary at work toward the teacher's effectiveness work at elementary School in Samarinda. The method used in this research was the quantitative approach. Data surveys collected from 178 teachers drawn at random. Data analysis using path analysis. The results showed that: 1) the principal leadership style, professional competence, and work discipline have a positive direct effect toward the effectiveness of teachers' work, and 2) the principal leadership style, and professional competence have a positive direct effect toward the work discipline
\end{abstract}

Keywords-leadership style, professional competence, work discipline, work effective

\section{INTRODUCTION}

Education is a conscious effort to prepare learners to play an active and positive role in their lives in the present and the future. The central government and local governments have been implementing educational programs from year to year. However, there are still many problems encountered such as: equity and expansion of primary and secondary education, low quality of education, lack of educational relevance, low education management and education funding that is not enough.

One of the problems of the low quality of education experienced in the city of Samarinda, East Kalimantan Province, the weak performance of teachers in carrying out teaching tasks caused by: the low of understanding of learning strategies, less skilled in class management, low achievement motivation, lack of discipline, low professional commitment and low time management capability. The problem has an impact on the low effectiveness of teacher work.

The low effectiveness of teacher work must be addressed immediately because it can hinder the achievement of the educational goals. Effectiveness is a measure of the level of achievement of organizational goals, including schools. Give stated 'Organization Theory and Design' defines the effectiveness of "That is, the greater the extent it which an organization's goals are met or surpassed, the greater its effectiveness". The effectiveness is related to the effort undertaken or the level of achievement of organizational goals
[1]. The greater the effort or the level of achievement, the greater its effectiveness. Further Miller in Hessel Nogi (2005: 138) give stated "Effectiveness be defined as the degree to which a social system achieves its goals. Effectiveness can be interpreted to what extent social systems have achieved their goals [2]. Effectiveness is a condition that shows the level of success of achieving organizational goals appropriately.

Give stated revealed that the quality of process and teaching result is influenced by interim and extern factor [3]. Thus, the effectiveness of teacher work can be influenced by two factors. The factor intern that allegedly confluence effectivities work teacher is competence and discipline of teacher work. While external factors which allegedly influential that is leadership style of principal.

Leadership style has an important role in improving the effectiveness of work and teachers discipline. Interpret the leadership is the art of influencing others to work optimally in completing tasks in an effort to achieve goals ("Leadership is the art of influencing others to their maximum performance to accomplish any task, objective or project ") [4]. leadership is the art of influencing others to strive for the achievement of common goals (Leadership is the art of mobilizing others to want to struggle for the shared aspirations)[5]. Meanwhile, according to Stogdill (1974) a leadership is the focus on group process, acceptance personality, and art affect the behavior of others.

The style of leadership is all the ways or techniques used by a leader in influencing, moving, directing, guiding, motivating, commanding, prohibiting, supervising, controlling subordinates, want to behave in accordance with the will of leaders in an effort to achieve goals. Six types of leadership, namely: personal leadership, nonperson leadership, authoritarian leadership, democratic leadership, paternalistic leadership, indigenous leadership. Five styles of leadership, namely autocratic, democratic, participatory, goal-oriented, and situational. Robbins mentions four leadership styles: the charismatic leadership style, the transactional leadership style, the transformational leadership style, visionary leadership. While Siagian mentions five kinds of leadership style are: autocratic leadership style, militaristic, paternalistic, charismatic, and democratic[6] 
Based on the opinion of the experts above can be argued that there are a number of styles / types of leadership that can be applied by a leader, example: (1) personal leadership, (2) nopersonal leadership, (3) authoritarian leadership), (4) democratic leadership, (5) paternalistic leadership, (6) indigenous leadership, (7) participative leadership, (8) goal-oriented leadership, 9) situational leadership, (10) militaristic leadership, (11) charismatic leadership, (12) transactional leadership, (13) transformational leadership, and (14) visionary leadership. As a leader, the principal has management skills to improve teacher performance. The principal is obliged to provide exemplary, disciplined coaching, education, training, motivation, and reward to raise awareness and responsibility for his task [7].

Leadership style is closely related to teacher performance. School heads must be able to carry out basic tasks and functions (EMASLIM) as educators, managers, administrators, supervisors, leaders, innovators and motivators Principals should be able to foster motivation, awareness, and selfdiscipline to carry out the task or job.

In addition to leadership style, professional competence also has an important role in improving work effectiveness and discipline of teachers work. According to Kenezevich competence is the ability to achieve goals. Defines competence as a basic characteristic of a person related to performance effective criteria, and / or excel in a particular job and situation ("Competency is underlying characteristic of an individual that is causally related to effective criteria and / or superior performance in a job or situation '.)[8]. In line with A competency is composed of skills, knowledge, and attitude, but in particular the consistent applications of those skills, knowledge [9]. The competence of the individual differences aspect associated with achievement, Competence shows the broad characteristic and the characteristic of a stable responsibility at the level of achievement that is the maximum opposite to the competence mental and physical work.

Competence is the knowledge, ability of intelligence, and skills controlled by a person who is a part of himself, so they can behave cognitively, affectively, and psychomotor with the expected results. While the professional competence of the ability of teachers in mastering knowledge in science, technology and / or the art and culture that he has received.

Professional competence is closely related to the effectiveness of the teacher [10]. Competent teachers are able to properly account for responsibilities, perform their roles and functions appropriately, and able educational goals. In addition to the above mentioned, also must understand the purpose of education, methods, and teaching models, mastering technology and assessing, cultivating a conducive learning environment, managing the class effectively. Thus the more competent will be more effectively perform the task or job.

Professional competence is the ability to master the knowledge of science, technology, and / or art and culture concluded that professional competence is positively related to teacher performance [11]. The better the mastering of professional competence the better the performance. In this case, discipline is one aspect of ability in competence. Teachers who are competent discipline perform the task, because it has the knowledge, understanding, skills, values, attitudes and interest realize in performance or performance (Gordon, 1988). Without the difficult competence it feels for the teacher to discipline perform the task, because the competence is the 'power' to take action. The more competent the discipline will carry out the task or job.

Give stated that teachers should have self-discipline, obedient and obedient perform tasks or work according to regulations [12]. Discipline is a conscious and responsible effort to regulate, control, control attitudes and behavior in order not to harm myself and others [13]. The disciplined teacher has a heightened awareness and sense of responsibility for his task, because discipline is an integral part of personal maturity.

In addition to leadership styles and competencies, the discipline of teachers also has an important role to work effectiveness. Without discipline, it is unlikely for the principal and teachers to achieve the goal effectively. Discipline is often associated with the success of a person or organization in achieving goals. Therefore teachers must be disciplined.

Discipline as a state in an organization that has regularity, so that employees behave according to the rules accepted within the organization [14]. Defines discipline as obedience or obedience in respecting and implementing a system that requires people to comply with the decisions, orders or regulations that apply [15]. Discipline synonymous with punishment, Discipline is only used when someone breaks the rules [16].

Work discipline is a work behavior that grows from awareness of roles and responsibilities to the organization [17]. Interpret the discipline of work is a situation that encourages to conduct activities according to norms or regulations set. Work discipline is related to obedience and obedience to perform the task or job according to the rules that apply. Discipline work to determine the success of teaching. In this case the teacher must discipline task or job [17]. The more discipline means the more effective. Without discipline is small for teachers to be able realize effectiveness of work.

Based on the problems and study of the theory above, the purpose of this research is to know: (1) influence of leadership style to work effectiveness, (2) influence of professional competence to work effectiveness, (3) influence of work discipline to work effectiveness, (4) leadership to work discipline, and (5) the influence of professional competence on work effectiveness.

\section{Methodology}

This research was conducted in elementary school (SD) in Samarinda, East Kalimantan Province. The method used was survey method with quantitative approach. Data analysis used was path analysis. Data were collected from 318 teachers drawn from six sub-districts. Proportional, with random sampling technique. Data collection uses instruments of test and non-test. The tests are used to collect teacher professional competence data. While non-test (scoring scale) is used to collect principal leadership style data, teacher work discipline, and effectiveness of teacher work. Before the tests and scoring scale are used, validity testing is performed with Product Moment correlation, and reliability using Cronbach Alpha technique. 
Data obtained from the results of the study were analyzed with descriptive and inferential analysis. Descriptive analysis is used to obtain a description of the characteristics of research variables. Whereas inferential analysis is used to test the hypothesis. Before the first analysis is done normality and linearity test. Direct influence between exogenous variables with endogenous variables. The effect is reflected from the path coefficient number.

\section{RESUlTS AND DisCUSSION}

Path coefficient analyzed by hypothesis that is: $\mathrm{p} \_y 1, \mathrm{p} \_\mathrm{y} 2$, p_y3, p_31, p_32. Calculation of the coefficient of Substructure I for: Effect of leadership style (X1), professional competence (X2), and work discipline (X3) on effectiveness (Y).

The result of substructure calculation I and II obtained coefficient value of path $\left(\mathrm{p} \_\mathrm{y} 1\right)=0,123 ;\left(\mathrm{p} \_\mathrm{y} 2\right)=0,649 ;\left(\mathrm{p} \_\mathrm{y} 3\right)$ $=0,142 ;\left(p_{3} 31\right)=0,190$, and $\left(p_{3} 32\right)=0,553$. The final model of the fourth line diagram of the variable is as Fig. 1.

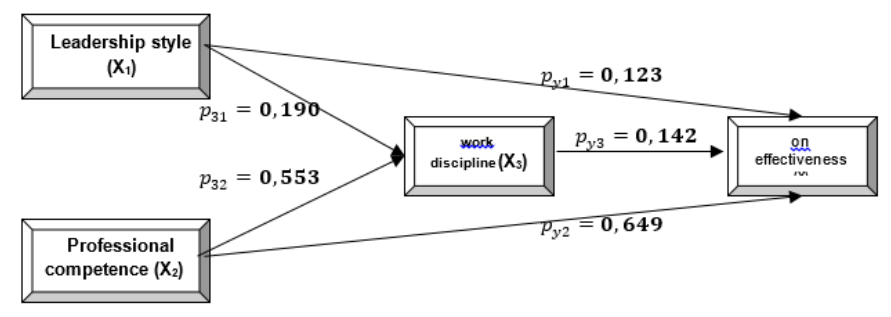

Fig. 1. Final Model Diagram

The result of substructure line coefficient calculation 1 can be seen in Table I. While substructure 2 can be seen in Table II.

TABLE I. COEFFICIENT OF LEADERSHIP STYLE PATH, PROFESSIONAL COMPETENCE, AND DISCIPLINE ON WORK EFFECTIVENESS COEFFICIENTS ${ }^{A}$

\begin{tabular}{|l|l|l|l|l|l|}
\hline \multirow{2}{*}{ Model } & \multicolumn{2}{|l|}{$\begin{array}{l}\text { Unstandardized } \\
\text { Coefficients }\end{array}$} & $\begin{array}{l}\text { Standardized } \\
\text { Coefficients }\end{array}$ & t & \multirow{2}{*}{ Sig. } \\
\cline { 2 - 5 } & $\mathrm{B}$ & $\begin{array}{l}\text { Std. } \\
\text { Error }\end{array}$ & Beta & & \\
\hline 1 (Constant) & -55.820 & 14.888 & & -3.749 & .000 \\
Leadership style & .174 & .070 & .123 & 2.475 & .014 \\
competence & 4.270 & .385 & .649 & 11.091 & .000 \\
Dicipline & .167 & .070 & .142 & 2.376 & .019 \\
\hline a. Dependent Variable: Effectiveness Y \\
\hline
\end{tabular}

TABLE II. COEFFICIENT OF LEADERSHIP LINE OF PATHWAY, COMPETENCE, PROFESSIONAL, TO WORK EFFECTIVENESS

Coefficients a
\begin{tabular}{|l|l|l|l|l|l|l|}
\hline \multirow{2}{*}{ Model } & \multicolumn{3}{l}{$\begin{array}{l}\text { Unstandardized } \\
\text { Coefficients }\end{array}$} & $\begin{array}{l}\text { Standardized } \\
\text { Coefficients }\end{array}$ & \multirow{2}{*}{ Sig. } \\
\cline { 2 - 7 } & B & $\begin{array}{l}\text { Std. } \\
\text { Error }\end{array}$ & Beta & & \\
\hline \multirow{3}{*}{1} & (Constant) & 32.507 & 15.870 & & 2.048 & .042 \\
\cline { 2 - 7 } & Leadership style & .229 & .074 & .190 & 3.107 & .002 \\
\hline & competence & 3.101 & .343 & .553 & 9.044 & .000 \\
\hline
\end{tabular}

a. Dependent Variable: dicipline (X3)

The output of Coefficients (tables 3 and 4) shows that all of the path coefficients studied have Sig values smaller than the value of $\alpha=0.05$ with the direction of positive coefficient.

The results showed that: (1) leadership style of principal has a direct positive effect on the effectiveness of teacher work. (2) Professional competence has a direct positive effect on teacher effectiveness. (3) Work discipline has a direct positive effect on teacher effectiveness. (4) The leadership style of principal has a direct positive effect on teacher work discipline. (5) Professional competence has a direct positive effect on teacher work discipline.

Based on the results of research conducted looks as follows. First, the leadership style of the principal has a direct positive effect on the effectiveness of teacher work. Good/ effective leadership is one thing that educators / teachers in the school really want. Good leadership/effective will increase the effectiveness of teacher work. Effective teachers need to be created, because they have a positive impact on achieving the goals and quality of education in schools.

The principal is the key to school success. Principals can improve teachers' effectiveness by applying democratic leadership styles [18]. As a result, leadership that can be accepted by teachers will support the achievement of the objectives, otherwise the leadership that cannot be accepted by teacher-teacher, besides not supporting the achievement of goals, also endanger the school by Ministry of National Educational.

Reveals that in applying democratic leadership, principals can implement school management functions, namely actuating function. In this case the principal can apply quality culture, improve professionalism, empower teachers through cooperation, improve willingness, making two-way communication, delegating tasks, giving directions, giving motivation and exemplary [11].

Second, professional competence has a direct positive effect on the effectiveness of teacher work. Teachers who are professionally competent will improve work effectiveness. Teachers who are professionally competent are indispensable in schools, as they will have a positive impact on improving the learning process and outcomes, work effectiveness, and achievement of educational goals.

As a leader, the principal can help improve teacher competence by enhancing the professionalism of teachers so that 
their skills, skills, and skills meet quality standards[10]. Because the effectiveness of teachers can be achieved if there is support professional competence of the teacher itself. Teacher competence can be improved in various ways, namely: mastering the educational base, teaching materials, making teaching programs, making assessment of learning outcomes. Competent teachers always try to improve the quality, professional standards, and code of ethics, and personality to support the performance and effectiveness of its work.

Third, the teacher's work discipline has a direct positive effect on the effectiveness of teacher work. The disciplined teacher is indispensable to the principal, and the students at the school [3]. Teacher discipline will improve teachers' effectiveness. Effective teachers are needed by the principal, as they will have a positive impact on students' behavior, achievement targets, and improving school quality.

Discipline can improve work effectiveness, One way that can be done by the teacher to improve the effectiveness of the work is to improve discipline [19]. Self-discipline does not appear just like that, so teachers should familiarize orderly and orderly life that starts from the family environment, foster motivation and self-awareness, obedient and obedient to regulation, and love and appreciate his work.

Fourth, the leadership style of the principal has a direct positive effect on the teacher's work discipline. In this case good leadership/effective is very expected by teachers[20]. Good/effective leadership will improve teachers' work discipline. Teachers who do the discipline of duties or work is necessary because it can have a positive impact on exemplary and disciplined coaching.

The key to the principal's success in improving teacher work discipline is to improve leadership [21]. Principals can apply democratic leadership styles, implement actuating functions to mobilize, influence and motivate teachers, so as to follow their will. Thus the teacher will be disciplined to carry out tasks or work, such as making lesson plans, implementing learning, assessing the process and learning outcomes, and provide remedial.

Fifth, professional competence has a positive slim effect on teacher work discipline [22]. A competent teacher is highly expected by the students, principals, and teachers themselves. Professionally competent teachers will improve work effectiveness, and have a positive impact on improving teacher professionalism, achieving curriculum targets, and improving the quality of learners. The effectiveness of teacher work can be improved by increasing the standard of academic qualification D-IV or Bachelor (S1), teacher certification, education and training. Because discipline is an integral part of personal maturity, the competent, motivated, awareness, responsibility, governing, controlling, controlling, obedient, and obedient teacher [23].

The results of the research presented above show that professional competence of teacher's greater influence on the effectiveness of teacher work, than the principal leadership style and discipline of teachers work. The competence of teachers is crucial to the success of teaching. Because teachers who are professionally competent have the commitment, and discipline to carry out the task or job. Learning result will not be effective if the teacher is not competent [24].

\section{CONCLUSION}

Based on the results and discussion, it can be put forward the conclusion of research as follows. The style of leadership has a direct positive effect on the effectiveness of work. This means that if the leadership style of the principal increases, then the effectiveness of teacher work will also increase. Conversely, if the leadership style of the principal decreased the effectiveness of teacher work also decreased.

Professional competence has a direct positive effect on the effectiveness of teacher work. This means that the improvement of professional competence of teachers will lead to increased effectiveness of teacher work. Conversely, the decrease in professional competence of teachers will lead to decreased effectiveness of teachers. Work discipline has a direct positive effect on the effectiveness of teacher work. This means that if the discipline of teacher work increases then, the effectiveness of work will increase. Conversely, if the teacher work discipline decreased then the effectiveness of teachers will also decrease.

The leadership style of the principal has a direct positive effect on the teacher's work discipline. This means that if the leadership style of the principal increases, then the teacher's work discipline will also increase. Conversely, if the leadership style of the principal decreases, then the teacher's work discipline will also decrease.

Professional competence has a direct positive effect on the teacher's work discipline. This means that if the professional competence of teachers increases, the teacher's teacher discipline will increase. Conversely, if the professional competence of teachers decreased, then the discipline of teachers will also decrease.

\section{REFERENCES}

[1] M. R. W. Hamstra, N. W. Van Yperen, B. Wisse, and K. Sassenberg, "Transformational and Transactional Leadership and Followers' Achievement Goals,” J. Bus. Psychol., vol. 29, no. 3, pp. 413-425, 2014.

[2] O. J. Akhigbe, "Human Resource Planning: A Key Factor in Ensuring the Effectiveness and Efficiency of Organization," J. Emerg. Trends Econ. Mangement Sci., vol. 4, no. 4, pp. 388-396, 2013.

[3] E. R. Hollins, “Teacher Preparation For Quality Teaching," J. Teach. Educ., vol. 62, no. 4, pp. 395-407, 2011.

[4] J. Cohen, "Cohen 1990.pdf," American Psychologist, vol. 45. pp. 13041312, 1990.

[5] C. L. Pearce, J. Elisabeth Hoch, H. Jeppe Jeppesen, and J. Wegge, "New forms of management: Shared and distributed leadership in organizations," Journal of Personnel Psychology, vol. 9, no. 4, pp. 151-

[6] T. S. Nanjundeswaras and D. R. Swamy, "Leadership Styles," Adv. Manag., vol. 7, no. 2, pp. 57-63, 2014.

[7] S. Marta, L. E. Leritz, and M. D. Mumford, "Leadership skills and the group performance: Situational demands, behavioral requirements, and planning," Leadership Quarterly, vol. 16, no. 1. pp. 97-120, 2005.

[8] L. M. Spencer and S. M. Spencer, "Competence at Work: Models for Superior Performance,” John Wiley Sons, pp. 1-372, 1993.

[9] K. M. Salleh and N. L. Sulaiman, "Human resource competencies and human resource roles in organization practice,” Int. J. Appl. Bus. Econ. Res., vol. 15, no. 4, pp. 377-385, 2017. 
[10] M. Liakopoulou, "The Professional Competence of Teachers: Which qualities, attitudes, skills and knowledge contribute to a teacher' $\mathrm{s}$ effectiveness ?,” Int. J. Humanit. Soc. Sci., vol. 1, no. 21, pp. 66-78, 2011.

[11] P. A. Ertmer and A. T. Ottenbreit-Leftwich, "Teacher technology change: How knowledge, confidence, beliefs, and culture intersect," J. Res. Technol. Educ., vol. 42, no. 3, pp. 255-284, 2010.

[12] D. Osher, G. G. Bear, J. R. Sprague, and W. Doyle, "How Can We Improve School Discipline?,” Educ. Res., vol. 39, no. 1, pp. 48-58, 2010.

[13] C. L. Suhler and P. S. Churchland, "Control: conscious and otherwise," Trends Cogn. Sci., vol. 13, no. 8, pp. 341-347, 2009

[14] G. Dessler, N. D. Cole, and V. L. Sutherland, "Human Resources Management,” Hum. Resour. Manag. Perspect., pp. 1-44, 2012.

[15] M. Wenglinsky and S. Milgram, "Obedience to Authority: An Experimental View.," Contemp. Sociol., vol. 4, no. 6, p. 613, 1975.

[16] M. Foucault, "Discipline and Punish: The Birth of the Prison," Contemp. Sociol., vol. 7, no. 5, pp. 1-333, 1978.

[17] J. Loughran, "Is teaching a discipline? Implications for teaching and teacher education," Teach. Teach., vol. 15, no. 2, pp. 189-203, 2009.

[18] H. D. Surjono, "The effects of multimedia and learning style on student achievement in online electronics course," Turkish Online J. Educ. Technol., vol. 14, no. 1, pp. 116-122, 2015.
[19] E. Garner, Effective Discipline - How to manage discipline at work. 2012.

[20] T. T. Nguyen, L. Mia, L. Winata, and V. K. Chong, "Effect of transformational-leadership style and management control system on managerial performance,” J. Bus. Res., vol. 70, pp. 202-213, 2017.

[21] B. K. Hardman, “Teachers' Perception of Their Principal's Leadership Style and the Effects on Student Achievement in Improving and NonImproving Schools," ProQuest LLC, no. January, 2011.

[22] M. Kunter, U. Klusmann, J. Baumert, D. Richter, T. Voss, and A. Hachfeld, "Professional competence of teachers: Effects on instructional quality and student development," J. Educ. Psychol., vol. 105, no. 3, pp. 805-820, 2013.

[23] X. Gao, G. Barkhuizen, and A. Chow, “"Nowadays, teachers are relatively obedient': Understanding primary school English teachers' conceptions of and drives for research in China," Lang. Teach. Res., vol. 15, no. 1, pp. 61-81, 2011.

[24] G. Devos, M. Tuytens, and H. Hulpia, "Teachers' Organizational Commitment: Examining the Mediating Effects of Distributed Leadership," Am. J. Educ., vol. 120, no. 2, pp. 205-231, 2014. 